\title{
Smart grid analysis and management in Colombia towards ETAP Real Time solution
}

\author{
Análisis y gestión de redes inteligentes en Colombia hacia la solución \\ ETAP Real Time
}

\author{
$\begin{array}{lll}\text { R. Franco-Manrique } & \text { E. Gómez-Luna }{ }^{1 *} \quad \text { C. A. Ramos-Sánchez }{ }^{2}\end{array}$ \\ Recibido 23 de Noviembre de 2016, aceptado 26 de Diciembre de 2017 \\ Received: November 26, 2016 Accepted: December 26, 2017
}

\begin{abstract}
RESUMEN
Este artículo presenta los avances de implementación de las llamadas Redes Inteligentes o Smart Grids en el mundo entero y el prospecto que tiene Colombia hacia la implementación de nuevas soluciones, principalmente aquellos avances y desarrollos tecnológicos realizados en las redes eléctricas, relacionados con el uso de software para el análisis y gestión de las mismas en diferentes escenarios con el fin de optimizar la gestión y operación del sistema eléctrico ante los nuevos retos que se tienen. Para este fin, primero se presenta el marco teórico en el que están situados y los avances que se han tenido en los últimos años, analizando los sistemas de medición, comunicación, control y seguridad tradicionales en comparación con las soluciones futuras.

Posteriormente, se recopila información general sobre los proyectos actuales que usan soluciones tal como ETAP Real Time, que involucran Redes Inteligentes. A su vez, se destacan las principales ventajas y desventajas que poseen las diversas soluciones implementadas, resaltando los vacíos técnicos y tecnológicos con respecto a la teoría consultada y el estado del arte actual.

Finalmente se presenta y describe la solución ETAP Real Time como alternativa integral para ayudar a resolver el desafío de implementación de las Redes Inteligentes en el mundo entero y aplicado al caso Colombiano.
\end{abstract}

Palabras clave: Redes inteligentes, medición inteligente, ETAP Real-Time, sistemas SCADA, microredes.

\begin{abstract}
The purpose of this paper is to present the advances in the implementation of the Smart Grids (SGs) in the whole world span and the prospectus of Colombia towards the implementation of new solutions. Mainly considering those technological developments and advances made in the electrical networks, related with the use of software for their analysis and management in different scenarios, to optimize the electrical system management and operation upon the new challenges that we have currently. For this matter, first is presented the theoretical framework which the SGs are focused and the advances in recent years, analyzing the metering, communication, security and control systems in comparison with future projected solutions.
\end{abstract}

1 Grupo de Investigación GITICAP. Potencia y Tecnologías Incorporadas S.A. Santiago de Cali, Colombia. Carrera 56, 2-50, Cali - Colombia. e-mail: rafaelfranco@pti-sa.com.co; eduardo.gomez@pti-sa.com.co

2 Departamento de Análisis de Sistemas de Potencia. Potencia y Tecnologías Incorporadas S.A. Santiago de Cali, Colombia. Carrera 56, 2-50, Cali - Colombia. e-mail: cesar.ramos@pti-sa.com.co

* Autor de correspondencia: eduardo.gomez@pti-sa.com.co 
Subsequently, it is collected the general information about the actual projects that use solutions, as ETAP Real Time, which involves SGs implementation. At the same time, pointing out the advantages and disadvantages that the diverse implemented solutions possess, highlighting the technical and technological gaps regarding the consulted theory and the current state-of-the-art.

Finally, the ETAP Real Time solution is presented as an integral alternative to help resolve the worldwide and Colombia implementation challenge of SGs.

Keywords: Smart grids, smart metering, ETAP Real-Time, scada systems, micro-grids.

\section{NOMENCLATURA}

$\begin{array}{ll}\text { AMI } & \text { - Advanced Metering Infrastructure } \\ \text { CMS } & \text { - Content Management Systems } \\ \text { DG } & \text { - Distributed Generation } \\ \text { DMS } & \text { - Demand Management System } \\ \text { EMS } & \text { - Energy Management System } \\ \text { HIS } & \text { - Historical Information System } \\ \text { IEC } & \text { - International Electrotechnical Commission } \\ \text { IEEE } & \text { - Institute of Electrical and Electronics } \\ \text { Engineers } \\ \text { IED } & \text { - Intelligent Electronic Devices } \\ \text { OMS } & \text { - Outages Management System } \\ \text { SGs } & \text { - Smart Grids } \\ \text { R\&D } & \text { - Research and development } \\ \text { FLIR } & \text { - Fault location, isolation and restoration } \\ \text { WAMS } & \text { - Wide Area Measurement System } \\ \text { SCADA } & \text { - Supervisory Control and Data Acquisition } \\ \text { IED } & \text { - Intelligent Electronic Devices } \\ \text { GIS } & \text { - Geographic information system } \\ \text { RT } & \text { - Real Time }\end{array}$

\section{INTRODUCTION}

In recent years, electrical power systems have grown up in a rapid and complex way, creating requirements and necessities each time more advanced in areas like Distributed Generation, DG, Advanced Metering, Communications, Control, Cybersecurity, among others [1].

Despite the advantages that suppose the DG implementation, like the emissions reduction, peak elimination, energy and power quality efficiency, among others [2]; it has associated certain problems that are portrayed in the dispatch capability, the high maintenance costs, the appropriate system management and the small producers/marketers participation in Electrical Markets. Furthermore, the network operators are facing multiple challenges in order to secure the continuity and service quality of electricity, due to the system expansion and the connection of additional energy sources to the grid [3].

According with the aforementioned, the metering elements play a fundamental role, because of them depends the system variables registry to increase its reliability. These employ technologies even more advanced like synchrophasors, that are recorded by Phasor Measurement Units, PMU, and allow to perform coordinated measures of the system with the objective to develop a communication system that joins sensors, control logic and actuators [4], migrating in this way from the traditional hierarchical structure towards an efficient and reliable system.

During the last years, it has emerged a worry regarding the power system infrastructure protection, because even more frequently are implemented robust information and communication technologies (ICT), specifically the ones known as Advanced Metering Infrastructure, AMI, that have been replacing the conventional SCADAs and their communication protocols, that are prone to the tampering, altering or sabotage [5]. So, a new panorama unfolds, in which is necessary to implement informatics security or cybersecurity strategies in power systems.

All the previous requires automation and real time simulation systems that allow to analyze, manage, access, measure and modify the main features of the power systems assets, that are not possible to apply with the traditional network infrastructure, boosting the necessity to implement Smart Grids [6].

Because of that, in this paper we explore different solutions or technical studies that has been implemented in Colombia, using as basis, the developments deployed all around the world during the last decades, that are looking to mitigate or solve the key issues in the deployment of Smart and Micro Grids in Colombia, giving a close look to the advances in this field around the world. 
According with this research, it is proposed the use of a computational and real-time hardware suite, that integrates the simulation, metering, supervision and control features, an implementation yet to fully develop in Colombia, as we are about to see.

\section{SMART AND MICRO GRIDS IN COLOMBIA}

The Smart Grids (SG) are sets of power systems fully integrated with the objective of replacing the traditional structure and contribute with the expansion of the electrical network increasing its efficiency [6].

According to Rahman [7], the SGs could be interpreted relating its necessity to fulfill the design, control, maintenance or operation requirements. For this particular author, they are divided into: Intelligent Transmission Network and Distribution Automation, Distributed Generation and Storage, Advanced Metering Infrastructure, and lastly Demand and Control Response as shown by shown by Figure 1 .

In this new scenario, the integration of control, communication, metering and security systems for the SGs acquire an special relevance, because of that, during the last years the interdependencies of such systems have been rising for the normal development of the worldwide social and economic activities as is evidenced in [8].
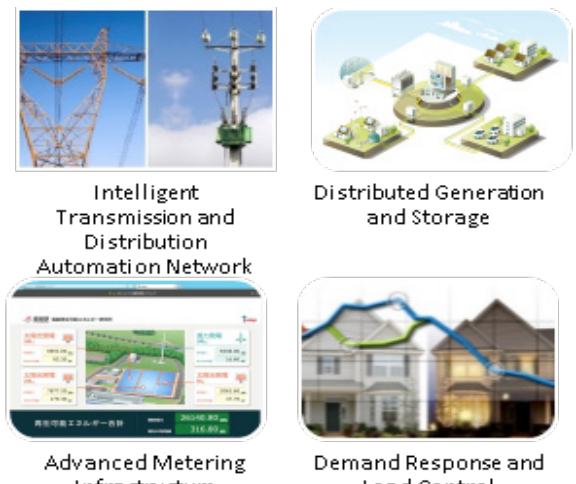

Distributed Generation and Storage

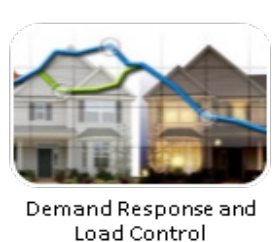
Load Control

Figure 1. Smart Grid Technologies Perception Quadrants

Growing at the same pace with the advances of Information and Communication Technologies, ICT and their application to power systems, also with the rising of sabotages, intrusions, intentional damages and component failures that have been presenting thanks to these interdependences between fields of engineering,

it is necessary to develop mechanisms of cybersecurity, this is an area not enough explored and implemented in the field of the up-to-date electrical engineering.

These Smart Grids integrate the Information and Communication Technology (ICT) in the electrical networks to optimize the energetic efficiency enabling the providers and consumers the opportunity to interchange information about electricity [9].

The ministry of Mining and Energy of Colombia, published in 2016, altogether with national and international entities of different sectors through the creation of an alliance named "Colombia Inteligente"; showed the results of an announcement performed in 2015, that had as objective develop the roadmap for the deployment of Smart Grids (SGs) and Micro-grids in the country [10]. This initiative of technical cooperation, called "Smart Grids Colombia Visión 2030", consisted of identifying the strategies, standards and regulations that demonstrated to possess the required adaptability and satisfy the necessary requirements to successfully accomplish the SGs implementation.

\section{SMART AND MICRO-GRIDS COMPONENTS}

According with the consulted information $[3,5,11]$, next is presented an overall summary of the elements that compose a present Smart Grid:

\section{Smart Metering}

The metering systems implementation requires of the realization of technical tasks and technological changes that must be reached at varied geographical and time scales. These tasks include feedback control and switching mechanisms with fast operation in substations, state estimators and contingency analysis, among other needs.

The SCADA technology, up-to-day used in the industries and largely in almost all of the generation, transmission and distribution systems, registers data from 2 to 4 seconds (until 10 seconds in some systems [12]) without assigning a time stamp, marking in the access point the time, in which they were accessed [11]. It is worth to mention that the data acquired by these systems is not synchronized. Because of that, right now are in experimental or development phase, new technologies turned to resolve this problem in great networks, one of them is the Wide Area Measurement System (WAMS) that uses the Advanced Metering Infrastructure (AMI). 
The key elements integrated in AMI are the Smart Meters and the Intelligent Electronic Devices, IED [6]. PMUs, developed at beginning of the 90s, are pioneer devices in the synchronized monitoring of the network and produce coordinated phasor measuring, also known as synchrophasors. These electronic devices based on computational algorithms, can register and storage a great quantity of information (including operational and not-operational) with a sampling frequency that depends on the device usage [12].

For this reason, research groups, governmental, national and international entities, associated with diverse industry sectors, lead investigations focused to solve the metering system challenges of the SG, implementing technologies like the aforementioned. With the objective to be able to perform analysis and real-time simulation to possess the capability of predicting events and adjust to the new challenges.

\section{Communications}

The SGs communications systems have been a study topic deeply evaluated and experimented by power system engineers, technicians and related professionals. These require of a communications structure that supports all the operations, switching and advanced real-time functionalities in a rapid way securing data integrity.

Since nineties, many electrical companies have been implementing SCADA systems with Outages Management System, OMS. These systems possess functions like human trouble-call handling, outage analysis and prediction, crew management and reliability reporting [13].

It is important to remind that SCADA systems possess as embedded solutions: OMS, DMS (Demand Management System), EMS (Energy Management System), CMS, HIS, which allow to monitor and manage an electrical power system. In this paper, we will make emphasis in OMS and DMS, being the most common used in the power systems.

The OMS possess connectivity maps of the distribution system and serve as a tool for the operators with the outage management, effectuating partial restorations and detection of nested outages.

The current requirements of power systems, that are striving to accomplish the transition towards
Smart Grids, makes that keep using just OMS systems be insufficient. Thus, it is necessary to deepen in the management of the sub-transmission, medium and low voltage systems; powering the operation, planning and the rest engineering tasks in a safe and efficient way ensuring the flexibility in a long term, not just managing the energy outages, but also the system demand. All of the previous requirements are fulfilled with the use of a DMS simultaneously with a OMS [13].

The DMS provides advanced application benefits like: network state estimator (real-time load calibration), load flow calculation, short-circuit, optimal feeder reconfiguration, losses minimization, load management, feeder voltage control, fault location, isolation and restoration (FLIR), among others [13].

In this field, it is important to note the GridSim tool, proposed by Anderson [4], which is composed by four groups of components: power system simulation, substation simulation, communication, data interchange and control center-like applications.

\section{Cybersecurity}

The development of the security layers, protection and resiliency for the SGs, with its interdependencies, it has turned into a great relevance topic for the social and economic activities that depend of the quality, stability and reliability of electric energy.

The key challenges for the SGs implementation, according to [5] are:

- Physical: Size, complexity, diversity of the network and the elements connected to it, associated to possible faults due to sabotage.

- Cybernetic: The cyberattacks, or communication network attacks of power systems, have increased during the last years. There have been listed occurrences of attacks like Denial of Service or Distributed Denial of Service (DoS, DDoS respectively) and are established the possible replies against those attacks, emphasizing in the preventive action.

In order to protect a system from the cybersecurity threats, it has to be implemented a layered security system that must consider the protection of: Personnel, Networks, Operative Systems, Applications and Databases. Exist a series of security requirements to be implemented in 
each layer, whose must include: Examination, Detection, Prevention, and Encryption.

The tools and techniques of cybersecurity are directed to reach three primary properties, Confidentiality, Integrity and Availability, CIA. To reach those properties, the design, development and implementation of cybersecurity technologies for protection, detection and response are required $[5,14]$.

With the development of cryptographic systems and their use in cybersecurity systems, confidentiality and integrity can be achieved. Safe communications systems currently use what is known as symmetric cryptography, or secret-key cryptography, it is called this way, because in the communication link edges, the key must remain secret [5].

In the future, many control devices will require security network devices, which act as compensation controls and secure the equipment. Before this happens, there exist various factors that make control systems cybersecurity still being a challenge, [5] points three of them:

- The clash of the procedural differences between the operations and the ICT team.

- The portability of the traditional control software towards the standardized platforms (subsidized by the government, in the case of U.S).

- The extensive lifecycle of the control systems.

The implementation of security mechanisms in power systems often has negative impacts in the data transmission speed that falls into a lowering in the execution, reading and modification of the components of the power system.

Given that the speed requirements for the distribution systems are especially high, no matter what standard is used, like IEC 62351 or IEEE 1686 , it is necessary to take into account the time restriction or latency tables in order to realize data encryption among the different layers of the used protocol.

We can conclude that the current system possesses the characteristics presented in Figure 2.

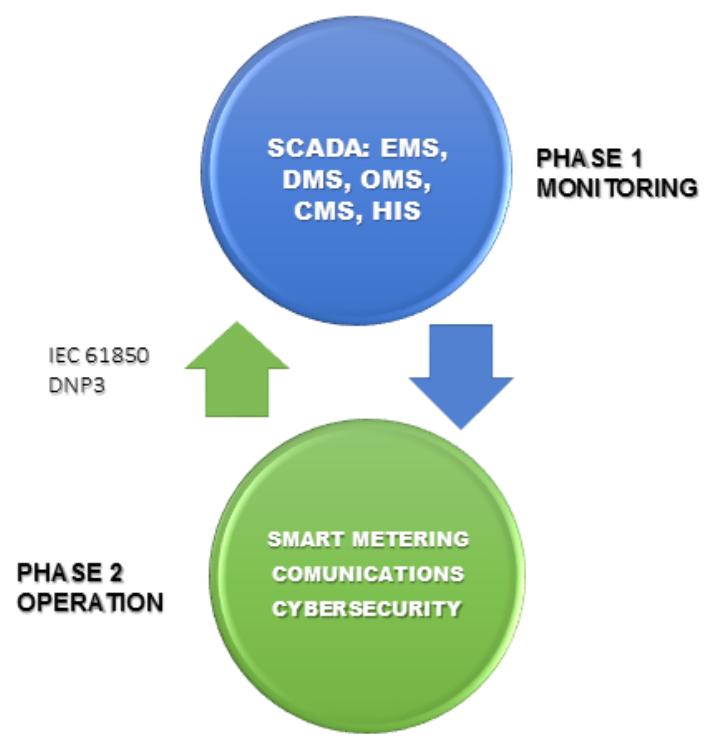

Figure 2. Implementation Phases of Smart Grid using traditional SCADAs.

Mantere et. al. [15], points out the importance of a Smart Grid system integrates smart metering, with advanced communication protocols and cybersecurity. Although they take into consideration that are present vulnerabilities related with users/utilities private information management, potential infrastructure attacks by the interception of communication packages and the necessity to develop a normative framework that upholds the cybersecurity practices to be implemented in the SGs.

\section{SGs Projects under Implementation in Colombia}

The SGs initiatives in Colombia have been realized through the collaboration of distinct governmental entities, national and multinational companies in the private sector. Some of the projects presented here are the most relevant, whether they are in planning, development or production phase, and serve as a radiography of current implementation de SGs [16].

The applied technologies in the diverse implementations include: AMI, Advanced Distribution Automation (ADA), Load and Actives Management, Electric Mobility and Distributed Energy Resources (DER) and Storage Systems (SS).

Among the most representative projects currently in progress in Colombia according to [10,16], we have:

- Smart Metering Multiservice Pilot Project (EPM-UNE) Medellín-Antioquía: Smart metering Project in electricity, water and natural 
- gas, for approximately a thousand clients, with the objective of assimilate the technology and measure the impacts in service quality, losses and commercial costs identification, among others.

- Yumbo Network Architecture Project (EPSA) Cali-Colombia: A project that looks to establish rules and criteria for the organization and development of the MV Network of Yumbo, based in technical-economic criteria and adapted to the particularities of the market. With the final objective to improve customer service quality, homogenize the structure, simplify the maintenance and network operation, among others.

- $\quad$ Electric Transportation Project (CELSIA-EPSA) Cali-Colombia: This project is developed to analyze the technological state of electric vehicles (EV), in Colombia, focused in the development lines and the applications to execute by the government entities, vehicle manufacturers and electrical sector companies, to achieve a stable entrance of the EVs in the market.

- Automation of underground distribution networks operation (CHEC) Caldas-Colombia: In this project, the CHEC is attempting to achieve a major operational effectiveness in the automation of underground distribution networks. It has been installed ten telecontrol equipment to make the supervision and remote operation from the control center, allowing to accelerate the switching circuits interconnection upon events presented in the system.

ICTs Telemetering Applications in Electricaribe, Barranquilla-Colombia: This project has as objective the evaluation of the actual network behavior with the standard communication protocol DLMSCOSEM and integrate in a same metering system, meters of different brands. In order to reduce the current losses level, which is pretty high given the manipulation of different devices, obtaining in this way a better energy control.

\section{SGs Implemented Projects in Colombia}

In the National University of Colombia (Universidad Nacional de Colombia), it was built a R\&D laboratory that has a platform focused in the development and evaluation of technologies related with the implementation of Smart Grids, called $\mathrm{LAB}+\mathrm{i}$, which currently works in the creation of pilot prototypes starting from a reference multi-layered model, theorized in this laboratory. This model possess the following Smart grid component layers: physical (P), interface (IF), communication (C), system (S), model (M), analysis (A) and intelligence (I) [6].

In the Bolivarian Pontificia University (Universidad Pontificia Bolivariana), was consolidated the design of a Micro Grid, which integrates ten subsystems managed in a centralized way. Those subsystems are composed by three meteorological stations created for the evaluation of the availability of the solar and wind resources, among other variables, a temperature and illumination automatic control system in a campus building, a biodigester, an Electric Vehicles feeding system, a street lighting LED circuit, and the control center that allows to visualize the variables of each subsystem, and two applications yet under development. In this way, it becomes the first national prototype a scale of a smart city [17].

Since the year 2009, research groups of the Colombia National University, the Industrial University of Santander (Universidad Industrial de Santander) and the Andes University (Universidad de los Andes) in collaboration with COLCIENCIAS have being developing the Project of Intelligent Electrical Distribution (SILICE I, II y III) [18]. In this project are tested the unconventional generation energy resources (biomass, solar, wind, among others), through the evaluation of different worldwide projects to develop the implementation framework of a Micro Grid in the electrical system of CODENSA [19].

It is evidenced that the scope of these projects are not presenting an integral solution, because they not englobe all the required or necessary components for the overall micro grids management, granting us, an opportunity to contribute and complement the existent solutions.

That is how, this paper will present a solution that allow the Smart and Micro grids, integrate all the required components, namely, smart metering, prediction, real-time simulation, energy management, communication, availability of the information for the management and/or control. Also, enabling the prediction upon external events that could happen given the modification of any equipment in the power system. 


\section{TREND CHANGE IN THE ELECTRICAL POWER SYSTEM MANAGEMENT}

Up until now, we have observed a technological and generational breakthrough that it has been manifesting in the deepening of different fields of investigation and development related all with the implementation of the aforementioned SGs.

Traditional systems, as have been shown, currently continue to be the leading systems in diverse industry sectors. SCADA systems, for example, are presented as a technology that is falling short in capabilities, yet widely used, despite the existence of communication and control protocols more advanced up-to-date [12]. For this reason, it has been made researches and proposed new theories with the objective to upgrade SCADAs to the Smart Grid demands [13, 20, 21, 22].

SCADA systems provide all the information about the industrial processes that include supervision, quality control, production control, data storage, and execute the entire real time interaction (this depends of the communication protocols used, with latencies to 5 seconds) with sensors and actuators. However, these systems lack of intelligence to supervise the power system, as other innovative solutions and applications used in other countries do.

Furthermore, multiple software for the control of an electrical power systems are required, besides from the different databases associated, that is to say, it is required of a software for GIS, SCADA, analysis, planning and power quality analysis. Figure 3 shows the actual panorama for the power systems.

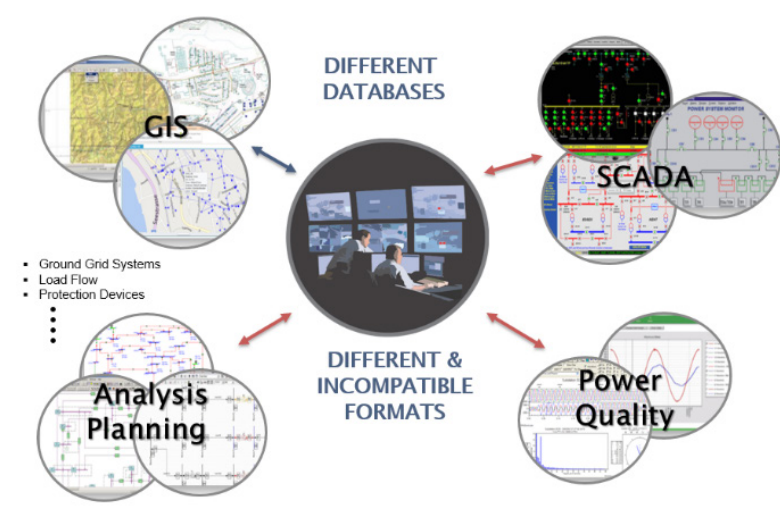

Figure 3. Current Panorama of Power Systems.
Control techniques for those systems are predefined for certain production scenarios, that are determined for the particular industry requirements [23], which do not permit to have the analysis, the resilience and the reliability necessaries, for the correct operation of power systems.

We may conclude that control systems, data acquisition and communications, currently used in power systems, are uncoupled for the solutions required for the system, according with the described by the Figure 3; its information is transmitted, stored and employed in a different way, because they cannot be considered in any way as SGs, given that they do not try to integrate those different industry subsystems, also they are not resilient against changes, reliable, predictive, and the parameter variations are not recorded or easily accessed from a HMI. In addition, they cannot execute different kinds of analysis over a unified model, because different models and unmatched technologies co-exist in the system, among many other disadvantages [14, 24].

As we will see further on, we present a multi-module solution that employs one single line diagram model, of the under study system, which is unified and permits to effectuate different kinds of power system studies both with the growing and complexity of itself, known as ETAP Real-Time.

\section{SMART AND MICRO GRIDS IMPLEMENTATION WITH ETAP REAL- TIME SOLUTION}

There are in the market, other software suites for the power system analysis, such as: ETAP, DIGSILENT, NEPLAN, PSCAD, SKM, CYME, SPARD, among many others [25], that allow to analyze networks in a traditional way realizing load flow, short circuit, frequency response and reliability analysis, among other studies.

Upon the necessities or requirements of electrical networks due to the changing trends, as the inclusion of Renewable Energy Sources, RES, topological shifts, system demand variations, it is not possible to realize within these software solutions, the analysis and management of the system starting from real-time data for the prediction and behavior of the system, for that reason we introduce the ETAP Real-Time solution 
[24]. Using this tool, the proposed Real-Time implementation phases within an electrical power system are shown in Figure 4.

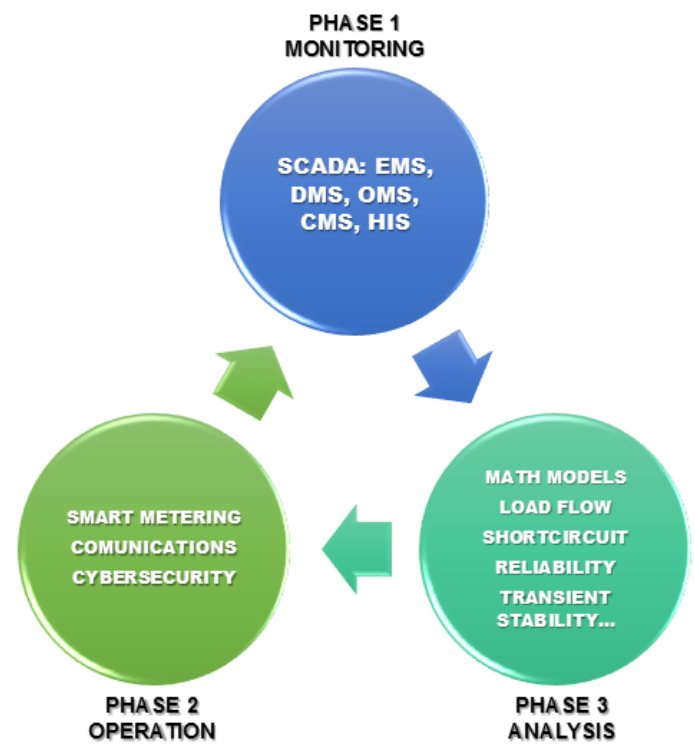

Figure 4. Real-Time Implementation Phases from SCADA systems.

Device operational models, as the onesembedded in SCADA systems, differ from the models used in power engineering consulting software, see Figure 5. As we have previously seen, the operation data centers are not working with detailed and real-time information to monitor, control, analyze and predict power system behavior [24]. Because of that, in this paper we propose the use of a solution that allows to integrate multiple applications to manage Smart and Micro Grids in an effective way.
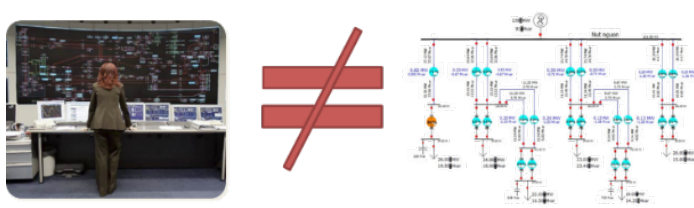

Figure 5. SCADA-based models vs models used in specialized consulting software

\section{ETAP-RT.solution}

The software called Electric Transient Analysis Program, ETAP, is an specialized program that makes the monitoring, analysis and power systems management, joining all the information in one single line diagram or mathematical model, providing this way, intelligence to the system, the model itself is fed with the necessary information for each analysis (Load Flow, Short circuit, Transient Stability, etc) [25, 26].
ETAP-RT presents a series of solutions to integrally manage Micro Grids, the following Figure 6 presents the available solutions for the monitoring, managing, prediction, simulation and control for the Micro Grids [30].

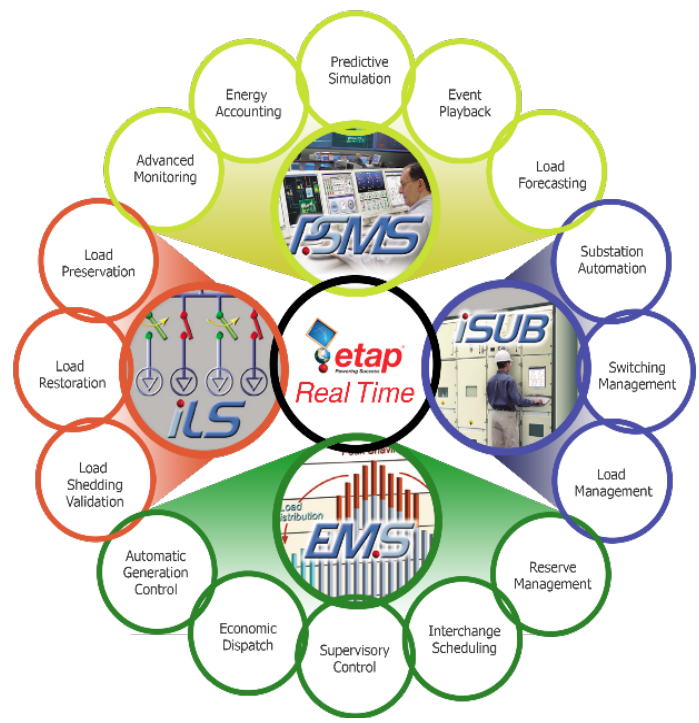

Figure 6. ETAP Real-Time Micro-grids Management Solutions [30].

PSMS (Power System Monitoring \& Simulation) This module allows to take advantage of all offline analysis functions using the same multiuser tool, eliminating the error in the module employed by traditional SCADAs, while provides intelligence for the operation and control of an electrical power system [27].

PSMS has the following sub-modules:

\section{$>$ Advanced Monitoring}

- Control and monitoring, estimations and trends, alarms and alerts.

- SLE Static Load Estimators: Uses the offline system model to provide precise results with real small contribution from itself, this way being useful for the validation of the field information.

\section{$>$ Predictive Simulation}

- Model Analysis under different scenarios, employing obtained real-time information.

- Simulation of Breaker Operations.

- Operator Training Environment.

- Remote Simulation via-website (executive interface). 


\section{Event Playback}

- Allows the user to replay past or recent system events and analyze from historical data, permitting to improve system operation, exploring alternatives of corrective or preventive future actions through decision making.

\section{$>$ Energy Accountability}

- Consumption and Energy Cost Tracking.

- User-defined Cost Functions and generator overheating rates.

- Decision making according to generation opportunities.

- Cost/Benefit Energy Analysis Report.

\section{$>$ Load Forecast}

- Predicts loading of seven days ahead.

- Predicts multiple load areas for each meter.

- Checks load predictions and climate conditions.

\section{EMS (Energy Management System)}

Smart Grids require of a distributed energy dispatch control system oriented to their necessities. Energy Management System has, among others, the following functionalities [27]:

\section{$\underline{\text { Automatic Generation Control }}$}

- Generation control of multiple areas.

- Frequency load control.

- MW and MVAr control.

\section{$>$ Economic Dispatch}

- Fuel costs minimization.

- Energy costs optimization.

\section{$>$ Supervisory Control}

- Control Systems Evaluation.

- Efficient control design.

- Operators training.

\section{Interchange Schedulin}

- Tariff analyzer.

- Cost analysis and energy management tools.

- Transaction Management Tools.
Reserve Management

- Identify the reserve capacity of the system.

- Monitor and maintain regulating, contingency, interruptible imports and on-demand reserves.

- Easily replaces the generation capacity and energy lost due to forced outages.

\section{ILS (Intelligent Load Shedding).}

The Intelligent Fast Load Shedding is a module that emerges due to the disadvantages of the traditional load shedding schemes, in which we can improve the response time, predict the decaying of the system frequency and make a fast, optimal and reliable decision from the load shedding operation [28, 29].

ILS has the following features:

\section{$>$ Load Preservation}

- Out-of-service time reduction for critical losses.

- Requirements reduction for the spinning reserve.

- Reliable system of Load Preservation.

$>$ Load Restoration

- Fast response against disturbances.

- Operational alerts for operation under marginal condition.

- $\quad$ Predict the system response after the load shedding operation.

\section{$>$ Load Shedding Validation}

- Capability of access and check the load shedding actions made with the recommendations.

- Option to simulate and check ILS recommendations.

\section{iSUB (Intelligent Substation)}

The Intelligent Substation module provides protection, control, automation, monitoring and communication capabilities taking part of a complete substation solution. Possess a distributed control system that interacts with the rest of ETAP Real-Time functions [30].

It has, among others, the following functionalities [31]:

$>$ Substation Automation

- Substation maintenance. 
- $\quad$ Sequence-of-Event, SOE.

- Fault detection.

\section{$>$ Switching Management}

- Sequence-of-Event Management.

- Security Procedures.

- Interlocks logic evaluation.

\section{$>$ Load Management}

- Operational Planning.

- Intelligent Load Management.

All of these solutions can be integrated to offer the most complete solution for the design, simulation, operation, control, optimization and automation for the generation, transmission, distribution, industrial and micro grids companies [27].

For their part, [32] realize the implementation of an intelligent load shedding system for a great industry using ETAP real-time software feature. Traditional load shedding is defined as the amount of load that needs to be shed, in order to keep in operation the remaining portion of the power system. The Intelligent Load Shedding implemented by ETAP, allows mapping of a complex and no-linear power system while preserves its configuration and predictively learns about the types of disturbances that could possibly appear, being response times faster than those of the traditionally used load shedding schemes [2].

The Smart Grids implementation has involved the partial integration of the components defined in the four quadrants theory suggested by Rahman [7]. Currently, ETAP Real Time is a worldwide project integrator for the implementation of Smart and Micro Grid systems for different international industries and organizations $[32,34,35,36]$. Where it has shown the advantages, and benefits of Smart Grids associated to electric power systems. Next are described some of the implemented projects around the world, using ETAP-RT, according with Table 1.

We observe that these solutions have been implemented in various countries around the world, obtaining appropriate results according to their requirements. Thus, it is observed that in Latin America, especially in Colombia, there has not been addressed solutions of these kind, which will bring many benefits for the electrical, industrial and research sectors of this country.

Based on the above, we could say that these types of solutions show benefits and important results for the guild and electrical sector in general. Furthermore, we can note this fact through the review of the state-of-art, the necessity to implement integral systems for the control and micro grid management associated to the electrical power systems.

\section{CONCLUSIONS}

ETAPReal-Time ${ }^{\mathrm{TM}}$ is an intelligent multi-modular solution that employs a unified model of the power system under analysis, it allows different study types, which is constantly fed and adapts to the necessities of every type of system, currently is the solution that integrates the quadrants theory proposed, as it was presented in this study.

Table 1. Worldwide ETAP Real-Time Implemented Projects [30].

\begin{tabular}{|c|c|c|c|c|c|c|c|c|c|c|c|c|c|}
\hline Company & Country & Market Sector & $\begin{array}{l}\text { Advanced } \\
\text { Monitoring }\end{array}$ & $\begin{array}{c}\text { Energy } \\
\text { Accounting }\end{array}$ & $\begin{array}{c}\text { Predictive } \\
\text { Simulation }\end{array}$ & \begin{tabular}{|l} 
Event \\
Playback
\end{tabular} & $\begin{array}{c}\text { Intelligent } \\
\text { Load } \\
\text { Shedding }\end{array}$ & $\begin{array}{c}\text { Automatic } \\
\text { Generation } \\
\text { Control }\end{array}$ & $\begin{array}{c}\text { Economic } \\
\text { Dispatch }\end{array}$ & $\begin{array}{c}\text { Supervisory } \\
\text { Control }\end{array}$ & \begin{tabular}{|c|} 
Interchange \\
Scheduling
\end{tabular} & \begin{tabular}{|c|} 
Load \\
Forecasting
\end{tabular} & Implementation Year \\
\hline Saudi Aramco & Saudi Arabia & Research & 可 & & & & & & & & & & 2004 \\
\hline Esso / ExxonMobil & Australia & Oil \& Gas & $\nabla$ & & 可 & & & & & & & & 2002 \\
\hline WeiHai Power & China & Distribution & 可 & & & & & & & & & & 2003 \\
\hline Jinan Steel & China & Industrial & V & & V & 可 & & & & & & & 2009 \\
\hline Shell / Equilon & United States & Oil \& Gas & 口 & & & & & & & 可 & & & 1997 \\
\hline Id aho National Lab & United States & Research & 可 & & & & & & & & & & 2006 \\
\hline GE Wind Energy & United States & Renewable & 口 & & 口 & 可 & & & & & & & 2007 \\
\hline $\begin{array}{l}\text { ExxonMobil } \\
\text { Chemical }\end{array}$ & United States & Oil \& Gas & च & च & 口 & च & & & & & & & 2010 \\
\hline $\begin{array}{c}\text { Shree Cements } \\
\text { Ltd. }\end{array}$ & India & Industrial & च & च & $\nabla$ & च & च & च & च & & च & & 2009 \\
\hline Pertamina & Indonesia & Oil \& Gas & V & & 可 & & & & & & & & 2001 \\
\hline PT Newmont & Indonesia & $\begin{array}{c}\text { Mining / } \\
\text { Distribution }\end{array}$ & च & & $\nabla$ & V & च & & & & & & 2006 \\
\hline Tanker Pacific & Singapore & Oil \& Gas & 可 & & & & 可 & & & & & & 2009 \\
\hline Lonmin & South Africa & Mining & 可 & & 可 & 可 & & & & & & & 2006 \\
\hline The Glow Group & Thailand & Generation & 向 & & 向 & V & & & & 可 & & & 2001 \\
\hline
\end{tabular}


It has been implemented ETAP Real-Time ${ }^{\mathrm{TM}}$ technology in different kind of industries around the world allowing engineers and operators, the smart visualization of systems at simulation level of maintenance operations, event playback and the execution of different kinds of power system analysis, enabling through the integration, cover most of the electric power system control. For this reason, at Latin-American countries, like Colombia, are starting to develop strategies toward the implementation of ETAP Real-Time solutions.

As found during this analysis, the current requirements of the electrical power systems at different voltage levels are increasing each time and it is a challenge to maintain the adequate system operation for power and control engineers, because of that, since the last decade manufacturers have been developing technologies that are looking for the implementation of Smart Grid attempting to cover all the necessary for the monitoring and control that they require.

The traditional control systems, like the SCADA, though obsoletes and their functioning philosophy is not accord with the actual power system requirements, generally have a lengthy lifecycle and they still are the prevailing technology for control and data acquisition. Given that, in this transitional period towards Smart Grids, it is necessary a solution that allows to integrate these kinds of systems with more advanced solutions, such as, offers the solution ETAP Real-Time ${ }^{\mathrm{TM}}$.

In this study, was evidenced the desire to upgrade and improve the current and future electrical systems (micro-grid, Smart-cities, etc) starting from solutions and tools that enable the integration of prediction and real-time simulation to the utility network operators, with the objective to allow the execution of functions, in an efficient and precise way, that support the network reliability, making a surveillance and operation, safe and secure at any moment, of the entire system.

The technological breakthrough in the development of Smart Grids have been in the framework of different isolated needs, to cite examples, Smart Grids focused only in Distribution systems, Micro Grids management with un-conventional energy sources and monitoring of industrial systems. Because of that, exist a few academic studies and government/electric sector fostered researches that have the objective to develop a solution that adapts to the necessities of any kind of Smart Grid. According to this, the proposed SGs implementation using ETAP Real-Time, it opens a new field for the research, analysis and testing of electrical power systems for Colombia and the rest of the world.

\section{ACKNOWLEDGMENTS}

The authors express their heartfelt thanks to the PTI S.A. Company for its support in the elaboration of this paper. They also thank COLCIENCIAS for its support for Project 54558, 2016, an approved project to access tax benefits, the Universidad del Valle and Universidad Nacional de Colombia, for its help provided us with this project.

\section{REFERENCES}

[1] L. Dong, Y. Li, K. Liu, T. Pu, and G. Liu. "Research on Smart Grid Simulation Framework Based on Distributed Intelligent System". International Conference on Power System Technology, pp. 20-22. 2014.

[2] P.Chiradeja. "Benefit of Distributed Generation: A Line Loss Reduction Analysis.” 2005 IEEE/PES Transm. Distrib. Conf. Expo. Asia Pacific, pp. 1-5. 2005.

[3] G.Rietveld,J.P.Braun, R.Martin,P.Wright,W.Heins, N. Ell, P. Clarkson and N. Zisky. "Measurement Infrastructure to Support the Reliable Operation of Smart Electrical Grids," IEEE Trans. Instrum. Meas. Vol. $64 \mathrm{~N}^{\circ}$ 6, pp. 1355-1363. 2015.

[4] D. Anderson, C. Zhao, C.H. Hauser, V. Venkatasubramanian, D. E. Bakken and A. Bose. "A virtual smart grid". IEEE Power Energy Mag. Vol. $10 \mathrm{~N}^{\circ}$ 1, pp. 49-57. 2012.

[5] J.Hull, H. Khurana, T. Markham and K. Staggs, "Staying in control: Cybersecurity and the modern electric grid". IEEE Power Energy Mag. Vol. $10 \mathrm{~N}^{\circ}$ 1, pp. 41-48. 2012.

[6] S. Tellez, D. Alvarez, W. Montano, C. Vargas, R. Cespedes, E. Parra and J. Rosero. "National Laboratory of Smart Grids (LAB+i) at the National University of Colombia-Bogota Campus". Transm. Distrib. Conf. Expo. - Lat. Am. (PES T D-LA), 2014 IEEE PES, pp. 1-6. 2014.

[7] S. Rahman. "Smart Grid : From Concept to Reality”. In Smart Grid 101 Series, pp. 37. 2011.

[8] S. M. Amin and A. M. Giacomoni, "Smart Grid- Safe, Secure, Self-Healing: Challenges and Opportunities in Power System Security, Resiliency, and Privacy". IEEE Power Energy Mag, pp. 33-40. February, 2012. 
[9] S.Lee, "NortheastAsiaPower SystemInterconnection andESS Based Balance Strategies in South Korea," vol. 100100152, pp. 4-8, 2014.

[10] J. José, M. Flórez, R. Andres, E. Martinez, and R. Ferreira, "Parte I," Smart Grids Colomb. Visión 2030, pp. 7-8, 2016.

[11] R. B. Bobbo, J. Dagle, E. Heine, H. Khurana, W. H. Sanders, P. Sauer and T. Yardley. "Enhancing grid measurements". IEEE Power Energy Mag. Vol. 10 N $^{\circ}$ 1, pp. 67-73. 2012.

[12] M. Kezunovic and A. Bose. "The future EMS design requirements". Proc. Annu. Hawaii Int. Conf. Syst. Sci., pp. 2354-2363. 2013.

[13] H. M. Gill. "Smart grid distribution automation for public power". 2010 IEEE PES Transm. Distrib. Conf. Expo. Smart Solut. a Chang. World, pp. 1-4. 2010.

[14] C. Andrés, D. Andrade and J.C. Hernández. "Smart Grid: Las TICs y la modernización de las redes de energía eléctrica-Estado del Arte". Sistemas y Telemática. Vol. 9, pp. 53-81. 2011.

[15] M. Mantere, S. Noponen, P. Olli and J. Salonen, "Network security monitoring in a small-scale smart-grid laboratory". Proc. - 9th Int. Conf. Availability, Reliab. Secur. ARES 2014, pp. 310-316. 2014.

[16] J.José and M. Flórez. "Parte IV Anexo 7. Iniciativas de redes inteligentes en Colombia". 2016.

[17] M. M. Llano, "La Micro-Red inteligente: una ciudad eficiente, en miniatura". Revista Universitas Científica, no. Junio, pp. 24-29. 2015.

[18] M. Ortiz-Rangel, L. Rueda-Vasquez, C. Duarte-Gualdron, J. Petit and G. Ordóñez-Plata, "Towards a smart city: Design of a domestic smart grid”. 2015 IEEE PES Innov. Smart Grid Technol. Lat. Am. ISGT LATAM 2015, pp. 863-868. 2016.

[19] José Lenin Morillo, "Proyecto SILICE Arquitectura y Conclusiones," in 2do Seminario de Energización con Fuentes Alternativas, 2014, p. 46.

[20] M. Geberslassie and B. Bitzer. "Future SCADA systems for decentralized distribution systems". Univ. Power Eng. Conf. (UPEC), 2010 45th Int., 2010.

[21] M. Regula, A. Otcenasova, M. Roch, R. Bodnar and M. Repak. "SCADA system with power quality monitoring in Smart Grid model". 2016.

[22] J.A.R. Carmona, J.C. M. Benítez and J.L. Garćia-Gervacio, "SCADA system design: A proposal for optimizing a production line".
2016 Int. Conf. Electron. Commun. Comput. CONIELECOMP 2016, pp. 192-197. 2016.

[23] M.B. Mollah and S.S. Islam. "Towards IEEE 802.22 based SCADA system for future distributed system”. 2012 Int. Conf. Informatics, Electron. Vision, ICIEV 2012, pp. 1075-1080. 2012.

[24] S.S. Hossain and K. Tanuj. "An Integrated \& unified model base approach from design to operation \& optimization of power system". In VIII Simposio Internacional sobre Calidad de la Energía Eléctrica, pp. 1-6. 2015.

[25] S. Hay and A. Ferguson. "A Review of Power System Modelling Platforms and Capabilities". The Institution of Engineering and Technology (IET). Paper 3 of 15, Part 3. 2015.

[26] L. Bam and W. Jewell, "Review: power system analysis software tools". Power Eng. Soc. Gen. Meet. 2005. IEEE, pp. 139-144. 2005.

[27] F. Farahmand, T. Khandelwal, J.J. Dai and F. Shokooh. "An enterprise approach to the interactive objectives and constraints of Smart Grids". 2011 IEEE PES Conf. Innov. Smart Grid Technol. - Middle East, ISGT Middle East 2011, pp. 1-6. 2011.

[28] R. Franco Manrique and C. A. Ramos Sánchez. "Deslastre de Carga Inteligente en Sistemas Eléctricos de Potencia". PetroQuiMex, Mexico, pp. 30-41. 2016.

[29] F. Kling. "What Your Smart Grid Needs From a Power Management System". Oper. Technol. Inc., pp. 1-8. August, 2010.

[30] OTI Inc. "ETAP Real Time Brochure.” OTI Inc., pp. 1-40. 2015.

[31] OTI Inc. "Energy Management System Software". 2016. [Online]. Available: http:// etap.com/energy-management-system/ interchange-scheduling-software.htm. [Accessed: 30-Sep-2016].

[32] F. Shokooh, J.J. Dai, S. Shokooh, J. Tastet, H. Castro, T. Khandelwal and G. Donner. "An intelligent load shedding (ILS) system application in a large industrial facility". Conf. Rec. - IAS Annu. Meet. (IEEE Ind. Appl. Soc. Vol. 1 N$^{\circ}$ 949, pp. 417-425. 2005.

[33] N. Locci and C. Muscas. "Hysteresis and eddy currents compensation in current transformers". IEEE Trans. Power Deliv. Vol. $16 \mathrm{~N}^{\circ}$ 2, pp. 154-159. 2001.

[34] S. Kulkarni and S. Sontakke. "Power System Analysis of a Microgrid using ETAP". $\mathrm{N}^{\circ} 5$, pp. 53-57. 2015. 
[35] ETAP Real Time Brochure, "Model-Driven Real-Time Solutions for Power Systems Model-Driven Enterprise Solution”, p. 16. 2015.

[36] R. Franco M. "Herramienta para la simulación en tiempo real de una microred aislada usando etap real time". Tesis de Maestría. Universidad del Valle, Colombia, pp. 1-90. Septiembre 2017. 